\title{
Dominação masculina e saúde: usos do corpo em jovens das camadas médias urbanas
}

\author{
Masculine domination and health: the uses \\ of the body in middle class urban youth
}

\begin{abstract}
This article discusses the representations that determine what is considered to be normal or deviational in the sexual behavior of men and women; how sexuality is valorized; and how the body is used in middle class urban youth in Rio de Janeiro ("cariocas"). The aim of this paper is to analyze the different discourses present in middle class carioca youth. Data were collected from questionnaires distributed in 1998-2000 among 1.279 middle class carioca men and women. The respondents were university-educated, with a monthly family income above $R \$ 2.000,00$. In the initial group, a total of 258 questionnaires were analyzed, 74 being from men and 184 from women between the ages of 17 and 24 years.
\end{abstract}

Key words Gender, Youth, Sexuality, Body, Domination, Health
Resumo $O$ artigo analisa os diferentes discursos presentes em jovens, a partir dos dados de uma pesquisa realizada, de 1998 a 2000, com 1.279 homens e mulheres das camadas médias cariocas, de nivel universitário, com renda familiar acima de $R \$ 2.000,00$, moradores da Zona Sul do Rio de Janeiro. Para as reflexões deste artigo, foram analisados, sob uma perspectiva qualitativa, 258 questionários aplicados em jovens de 17 a 24 anos, com o objetivo de discutir a dominação masculina, com seus imperativos sociais de usos do corpo e seus reflexos na saúde física e psicológica dos indivíduos. Por meio dos dados encontrados, pode-se concluir que a busca de um determinado modelo de corpo pode significar, para muitos indivíduos contemporâneos, a submissão a uma espécie de "violência simbólica" imposta àqueles que não se disciplinam para se enquadrar nos padrões exigidos.

Palavras-chave Gênero, Juventude, Sexualidade, Corpo, Dominação, Saúde

\footnotetext{
1 Departamento

de Antropologia Cultural, Programa de Pós-Graduação em Sociologia e Antropologia, Instituto de Filosofia e Ciências Sociais, UFRJ. Largo de São Francisco, no 1, sala 420, 20051-070, Rio de Janeiro RJ. miriangg@uol.com.br
} 


\section{Introdução}

Apesar de ter escrito o clássico As técnicas corporais, em 1934, o antropólogo francês Marcel Mauss continua uma referência obrigatória para aqueles que querem compreender um fenômeno característico dos tempos atuais: a valorização de um determinado tipo de corpo masculino e feminino. Para tanto, dois conceitos presentes em seu texto são fundamentais: o de "técnicas corporais" e o de "imitação prestigiosa”. Para Mauss (1974), o conjunto de hábitos, costumes, crenças e tradições que caracterizam uma cultura também se refere ao corpo. Assim, há uma construção cultural do corpo, com uma valorização de certos atributos e comportamentos em detrimento de outros, fazendo com que haja um corpo típico para cada sociedade. Esse corpo, que pode variar de acordo com o contexto histórico e cultural, é adquirido pelos membros da sociedade por meio da "imitação prestigiosa": os indivíduos imitam atos, comportamentos e corpos que obtiveram êxito. O autor chama atenção para o fato de que as técnicas corporais variam não simplesmente com os indivíduos e suas imitações, mas, sobretudo, com as sociedades, as educações, as conveniências e as modas, com os prestígios.

Essa concepção antropológica sobre a construção do corpo e dos comportamentos tem sido fundamental para a pesquisa que venho realizando, desde 1998, intitulada "Mudanças nos papéis de gênero, sexualidade e conjugalidade: um estudo antropológico das representações sobre o masculino e feminino nas camadas médias urbanas". Procura-se discutir, nesta pesquisa, as representações de gênero, a valorização da sexualidade e os diferentes usos do corpo, a partir dos dados de questionários aplicados em 1.279 homens e mulheres das camadas médias cariocas, de 17 a 50 anos, de nível universitário e renda familiar acima de $\mathrm{R} \$ 2.000,00$. Os questionários foram aplicados por alunos do curso de ciências sociais do Instituto de Filosofia e Ciências Sociais (Universidade Federal do Rio de Janeiro) em indivíduos de suas redes de relação que correspondessem ao perfil das camadas médias (renda, idade, escolaridade, moradia). Para as reflexões presentes neste artigo, foram analisados, principalmente, 258 questionários aplicados em jovens de 17 a 24 anos, com o objetivo de discutir a dominação masculina, com seus imperativos sociais de usos do corpo e seus reflexos na saúde física e psicológica dos indivíduos contemporâneos. Como fontes secundá- rias de análise, foram utilizadas matérias e pesquisas encontradas na internet (no site Uolteen) e em publicações nacionais (revista Isto É). É importante destacar que, apesar de ter como base uma pesquisa quantitativa, as reflexões aqui realizadas estão centradas em uma perspectiva qualitativa, buscando problematizar questões que, nem sempre, são expressivas numericamente (Goldenberg, 1997).

\section{Diferenças de gênero no discurso sobre o sexo}

A idade em que os jovens do sexo masculino afirmam ter se iniciado sexualmente varia de 13 a 23 anos, sendo que o maior número de respostas se concentra na idade de 16 anos e, em seguida, 15 anos. Entre as mulheres, $17 \%$ declaram-se virgens, o que chama atenção pela diferença em relação às respostas masculinas, em que apenas $4 \%$ se diz virgem. A idade em que as jovens afirmam ter deixado de ser virgens varia de 12 a 22 anos. A idade mais citada foi a de 16 anos, seguida da de 17 e 18 anos. Pode-se observar que as mulheres com mais de 20 anos que não perderam a virgindade se percebem como desviantes (Becker, 1977) em termos de comportamento sexual, uma vez que cinco pesquisadas, da faixa dos 21 a 30 anos, utilizam "ainda" ao revelar a virgindade ("ainda sou virgem").

As respostas dos pesquisados sobre a primeira relação sexual permitem perceber uma tendência: conforme a faixa etária diminui, a perda da virgindade ocorre mais tarde para os homens e mais cedo para as mulheres. Este dado pode ser observado ao se comparar os jovens com os homens pesquisados de 31 a 50 anos que tendiam a ter a primeira relação sexual em torno dos 14 anos, enquanto as mulheres pesquisadas dessa mesma faixa etária disseram ter tido sua primeira relação sexual aos 20 anos ou mais.

Ao perguntar "Com quantas pessoas teve relações sexuais?”, o que mais chama a atenção nas respostas masculinas é a imprecisão, encontrada em $28 \%$ das respostas: "mais ou menos 10 ", "mais ou menos 25 ", "aproximadamente 53", "muitas, perdi a conta", "com sinceridade, não lembro o número certo, mas em torno de 35 a 50 pessoas", "não me lembro, foram muitas", "um montão!!!”. O discurso masculino parece querer ressaltar, com esta imprecisão, que não lembra de suas parceiras sexuais ou que nem todas foram significativas. Entre as respostas masculinas precisas, $19,5 \%$ disseram ter tido 
uma única parceira; enquanto $48 \%$ afirmam ter tido de 2 a 5 parceiras; $24 \%$, entre 6 a 10 parceiras; $6,5 \%$, entre 11 a 20 parceiras; e $2 \%$ disseram ter tido mais de 20 parceiras.

As respostas femininas foram muito mais precisas, contrastando fortemente com as masculinas: somente $2 \%$ das jovens foram vagas em suas respostas: "acho que sete", "nove, no máximo". As jovens lembram de seus parceiros sexuais indicando que eles foram importantes em suas vidas, com a conhecida associação feminina entre sexo e afetividade (Goldenberg, 2000). Das respostas femininas precisas, $33 \%$ afirmam ter tido um único parceiro; $46 \%$, entre 2 a 5 parceiros; $15 \%$, entre 6 a 10 parceiros; $5 \%$, entre 11 a 20 parceiros; e $1 \%$ disse ter tido mais de 20 parceiros.

Pode-se argumentar que o abismo entre os gêneros, quando se trata da primeira relação sexual, vem diminuindo. Quando a questão é o número de parceiros sexuais, a distância entre homens e mulheres sofreu menos alterações, já que as respostas femininas, de todas as faixas etárias, apontam para números inferiores aos masculinos. Além disso, e talvez o mais importante, o posicionamento dos homens diante da pergunta é diferente. Enquanto eles apresentam respostas imprecisas, elas, em sua grande maioria, demonstram saber exatamente com quantas pessoas tiveram relações sexuais. Percebe-se, portanto, apesar de transformações significativas do comportamento sexual masculino e feminino, principalmente no que diz respeito à iniciação sexual, a existência de uma "dupla moral", que prescreve multiplicidade de parceiros sexuais para os homens e restringe os parceiros sexuais para as mulheres.

\section{Tamanho é documento?}

As respostas femininas para o que invejam em um homem podem ser classificadas em: "vantagens sociais" e "vantagens corporais". O que as mulheres mais invejam nos homens é a liberdade. É interessante ressaltar a referência ao modo masculino de "fazer xixi" que aparece em $8 \%$ das respostas ("o modo como eles fazem xixi facilita a escolha do lugar"; "poder fazer xixi em qualquer lugar”).

Poucos homens responderam à questão "o que você mais inveja em um homem?”, sendo que $16 \%$ das respostas podem ser associadas a um modelo de masculinidade hegemônica (Kimmel, 1998): prestígio, inteligência, dinheiro, in- dependência, sucesso, poder. Oito por cento das respostas estão ligadas a aspectos físicos, como: "um corpo malhado", "um belo corpo" e "perna e bunda”.

Vale a pena destacar que, quando perguntados sobre o que mais invejam em uma mulher, cerca de $40 \%$ dos homens pesquisados afirmam que não invejam nada. Apenas 7\% dizem invejar a capacidade da mulher ter filhos: "dar à luz" e "poder gerar e conceber um filho".

Ao observar as respostas em todas as faixas etárias pesquisadas, dos 17 aos 50 anos, percebe-se que oito pesquisadas respondem que o que mais invejam em um homem é o "pênis", enquanto três pesquisados revelam que o que mais invejam em outros homens é o "pênis grande”. Nenhuma mulher qualificou o pênis e nenhum homem disse simplesmente "pênis". Este dado pode indicar que as mulheres invejam a condição masculina privilegiada na sociedade, enquanto os homens invejam um símbolo de potência, força e virilidade.

É interessante perceber que duas jovens consideram como defeito no homem o pênis grande ("peru muito grande"; "pau grande"), o que parece ir contra as expectativas masculinas sobre o tema. Ao comparar essas respostas às da pergunta "o que mais atrai em um homem?", em que o pênis é citado quatro vezes, é possível pensar que o órgão sexual masculino pode até ser atraente para algumas das pesquisadas, mas o fato de ser grande não é necessariamente percebido como qualidade por elas. Já dois pesquisados apontam como defeito o "pau pequeno".

Outro dado que merece ser ressaltado é que para as jovens, ao se descreverem para um anúncio proposto ("Se você escrevesse um anúncio com o objetivo de encontrar um parceiro, como você se descreveria? Como você escreveria o que procura em um parceiro?”), a beleza é uma característica fundamental ("linda", "bonitinha", "bonitinha de corpo", "bonita”). Em relação ao peso, as jovens destacam que são "magras”, citam o peso: "52 kg", "58 kg” e "60 kg” ou "manequim 38”. Não foram encontradas mulheres que se definem como gordas ou gordinhas.

Os jovens do sexo masculino enfatizam a altura em suas descrições, dizem que são "altos” ou descrevem a altura que vai de 1,74 a 1,85 m. Não foi encontrada nenhuma resposta em que o pesquisado se define como baixo. O peso é mencionado apenas em quatro respostas, de 64 a 99 quilos. Alguns ressaltam em suas respostas o porte físico: "corpo físico atlético e bem dotado" "bom porte físico". 
Podemos observar alguns dados curiosos ao comparar as respostas masculinas e femininas para a proposta de anúncio. Em relação à altura, nenhum homem afirmou ser baixo e nenhum se descreve como menor que 1,74 m. Enquanto as mulheres procuram chamar a atenção para a sua magreza, os homens parecem muito mais preocupados com a altura e a força física. As mulheres que citam o peso indicam um mínimo de 52 quilos e um máximo de 60 quilos, uma variação de 8 quilos. Já os homens têm uma variação entre o máximo (99 quilos) e o mínimo (64 quilos) de 35 quilos, o que pode ser um indicativo de que no caso masculino o peso não é considerado tão relevante quanto a altura e a força. Nas respostas femininas observa-se uma ocorrência significativa de jovens que se definem como bonitas ou atraentes, indicando que a beleza é considerada um fator importante ao se apresentarem a um suposto pretendente. Os homens, ao contrário, não parecem achar significativo o fato de serem ou não bonitos ao se descreverem a uma possível parceira, já que somente um homem se define como "bonito".

Pesquisando na Internet, encontrei no site UolTeen cartas de adolescentes enviadas para a seção Pronto-Socorro. Das cartas enviadas, dezenas são de adolescentes preocupados com o tamanho do pênis. Selecionei alguns trechos que demonstram que tamanho é documento para muitos deles.

Sou um garoto muito cobiçado aqui na minha cidade, e muitas garotas são a fim de ficar comigo e transar. Tenho 17 anos e ainda sou virgem, mas praticamente ninguém sabe disso. Tenho muita vergonha porque acho que meu pênis é pequeno: ele tem + ou $-14 \mathrm{~cm}$, e pra minha idade é pequeno. Tenho vergonha de tirar a roupa perto de meninas por isso. Vi em uma pesquisa que a média do pênis do brasileiro é + ou $-15 \mathrm{~cm}$, mas por que todos que eu conheço têm de $17 \mathrm{~cm}$ pra cima? Tenho medo de transar com uma menina e ela espathar o fato. Obrigado pela atenção e até mais.

Eu gostaria de saber qual é o tamanho, em média, de um pênis, e até que idade ele se desenvolve. E sabe aquele aparelho que tem uma bombinha? Ele funciona para aumentar o tamanho do pênis? Me tira esse grilo, pois acho que meu pênis não é o suficiente. Valeu!

Uma enquete no mesmo site comprova esta preocupação ao perguntar: "Se pudesse fazer uma mágica, o que você mudaria em seu corpo?". Dos 5.487 votos dos “meninos", as principais respostas foram: "Teria o corpo todo ma- lhado" (28\%), "aumentaria o tamanho do meu pinto" (24\%), "não mudaria nada, deste jeito está bom" (14\%). Já dos 3.515 votos das "meninas" $32 \%$ disseram "teria o corpo todo malhado". Apenas 7\% responderam que "não mudaria nada, deste jeito está bom".

Se os jovens querem ser fortes e musculosos, e ter um pênis grande, as jovens querem ser magras e bonitas. Esta obsessão das jovens com o peso gerou uma cultura da magreza que tem uma de suas manifestações mais perversas na proliferação de sites na Internet que incentivam a anorexia. Uma reportagem da revista Isto $\hat{E}$ (25/10/2002) revelou que um exército de adolescentes está usando a Internet para ensinar outras jovens a serem anoréxicas, pregando a inapetência e a autopunição sempre que comerem. As páginas são assustadoras com fotografias de meninas esquálidas apontadas como modelos de beleza, dicas para enganar os pais e amigos para fingir que estão alimentadas e formas de se punir caso comam algo que engorda. Os sites divulgam os seguintes "mandamentos": Você não deve comer sem se sentir culpada. Você não deve comer algo que engorda sem se punir depois. Ser magra é mais importante do que ser saudável. Você nunca está magra. Ser magra é a coisa mais importante que existe. Outras dicas são: Não engula! Morda, mastigue e jogue fora! Durma pouco. Dessa forma você queima mais calorias. Limpe banheiros ou ambientes bem sujos. Você perde a fome. Diga que você vai comer no quarto e jogue a comida fora. Em casa, diga que vai comer com os amigos. Aos amigos você diz que já comeu em casa.

Durante muito tempo, a preocupação com a aparência e com determinado modelo de corpo ficou restrita (e permitida) às mulheres. No entanto, na sociedade contemporânea, alguns pesquisadores têm se preocupado em refletir sobre as possíveis conseqüências, também para os homens, da perseguição de um determinado modelo de corpo. Badinter (1993), por exemplo, acredita que o refúgio no álcool e nas drogas e, também, a impotência são frutos da fragilidade masculina diante de novos imperativos sociais, que impõem novas exigências e obrigações sexuais. A autora afirma que o ideal viril custa muito caro para os homens, que fazem esforços enormes para se adequarem a um modelo masculino que supervaloriza o tamanho do pênis e provoca a obsessão pelo desempenho sexual, causando angústia, depressão, ansiedade, stress, dificuldades afetivas, medo do fracasso e comportamentos compensatórios poten- 
cialmente perigosos e destruidores. Além disso, ela lembra que os homens procuram médicos e psicólogos com muito menos freqüência e facilidade do que as mulheres, mantendo em segredo, como um estigma a ser escondido (Goffman, 1975), suas doenças e preocupações. Não é de se estranhar, portanto, o fato de os homens morrerem bem mais cedo do que as mulheres.

Um trabalho interessante sobre a obsessão masculina em responder a um ideal de "ser homem", ancorado em um corpo musculoso e no tamanho do pênis, é "O complexo de Adonis". Seus autores afirmam que milhões de homens nos Estados Unidos estão sacrificando aspectos importantes de suas vidas para se exercitarem compulsivamente nas academias. Milhões de dólares são gastos em suplementos alimentares e esteróides anabolizantes, que causam câncer, hepatite e outras doenças graves. Além destas "drogas perigosas", os distúrbios alimentares são cada vez mais freqüentes neste universo. Os autores revelam que mais de um milhão de norte-americanos, especialmente adolescentes e meninos, desenvolveram o "distúrbio dismórfico corporal", representado por uma preocupação excessiva com supostas falhas na aparência, como "o tórax pequeno ou o pênis diminuto". Basta, segundo os autores, uma rápida olhada na Internet para descobrir o exagero de técnicas de aumento de pênis hoje comercializadas, sendo "a indústria do aumento do pênis" uma parte significativa da crescente "indústria da imagem corporal masculina", estimulando e aumentando as inseguranças dos homens a respeito dos seus corpos. O estudo destaca que estes homens, meninos e adolescentes, sofrem silenciosamente, em segredo, não conversam sobre seus problemas, pois, em nossa sociedade, os "homens de verdade" não devem demonstrar preocupação com a aparência, pois podem ser considerados "afeminados" ou "gays".

Bourdieu (1999), em A dominação masculi$n a$, afirma que os homens tendem a se mostrar insatisfeitos com as partes de seu corpo que consideram "pequenas demais" enquanto as mulheres dirigem suas críticas às regiões de seu corpo que the parecem "grandes demais". O autor acredita que a dominação masculina, que constitui as mulheres como objetos simbólicos, tem por efeito colocá-las em permanente estado de insegurança corporal, ou melhor, de dependência simbólica: elas existem primeiro pelo, e para o, olhar dos outros, como objetos receptivos, atraentes, disponíveis. Delas se espera que sejam "femininas", ou seja, sorridentes, sim- páticas, atenciosas, submissas, discretas, contidas ou até mesmo apagadas. Neste caso, ser magra contribui para esta concepção de "ser mulher". Sob o olhar dos outros, as mulheres se vêem obrigadas a experimentar constantemente a distância entre o corpo real, a que estão presas, e o corpo ideal, o qual procuram infatigavelmente alcançar.

No entanto, para Bourdieu (1999), a estrutura impõe suas pressões aos dois termos da relação de dominação, portanto aos próprios dominantes, que são "dominados por sua dominação", fazendo um esforço desesperado, e bastante patético, mesmo em sua triunfal inconsciência, que todo homem tem que fazer para estar à altura de sua idéia infantil de homem. A preocupação com a altura, força física, potência, poder, virilidade e, particularmente, com o tamanho do pênis, pode ser vista como exemplo desta dominação que o dominante também sofre.

\section{Considerações finais}

Os dados apresentados nos ajudam a perceber que exigências terríveis a respeito de um determinado modelo de corpo escravizam não apenas as mulheres mas também os homens. Como lembra Rodrigues (1979), as sociedades são capazes de levar os seus membros, por meios puramente simbólicos, à doença e à morte: incutindo-lhes a perda da vontade de viver, fazendo-os deprimidos, abalando-lhes de toda forma o sistema nervoso, consumindo as suas energias físicas, marginalizando-os socialmente, privando-os de todos os pontos de referência afetivos, desintegrando-os de tal forma que num determinado ponto a morte passa a ser um simples detathe biológico. No caso estudado, a busca de um determinado corpo, de acordo com os modelos socialmente legitimados, pode levar homens e mulheres a doenças e, também, à morte, simbólica ou até mesmo biológica. Não apenas por tomarem como base padrões muitas vezes fora da possibilidade humana, condenados pelos órgãos mundiais de saúde, mas principalmente pela "violência simbólica" (Bourdieu, 1999) a qual são submetidos caso não consigam enquadrar seus corpos nesses modelos.

Pode-se concluir que a aparente liberação dos corpos, sugerida por sua atual onipresença na publicidade, na mídia e nas interações cotidianas, tem por trás um processo de "imitação", como queria Mauss, que se empreende e se legitima através dela. Devido a mais nova moral, a 
da "boa forma" (Goldenberg \& Ramos, 2002), a exposição do corpo, em nossos dias, não exige dos indivíduos apenas o controle de suas pulsões, mas também o (auto)controle de sua aparência física.

É interessante destacar o paradoxo que o culto ao corpo gera nesta cultura das camadas médias urbanas. Quanto mais se impõe o ideal de autonomia individual, mais aumenta a exigência de conformidade aos modelos sociais do corpo. Se é verdade que o corpo se emancipou de muitas de suas antigas prisões sexuais, procriadoras ou indumentárias; ele se encontra, atualmente, submetido a novas coerções estéticas. A obsessão com a magreza, a multiplicação das academias de musculação, o uso de anabolizantes, são apenas alguns dos exemplos que testemunham o poder de normalização (ou padronização) dos modelos, um desejo maior de conformidade estética que se choca com o ideal individualista e sua exigência de singularização dos sujeitos.

\section{Referências bibliográficas}

Badinter E 1993. XY sobre a identidade masculina. Ed. Nova Fronteira, Rio de Janeiro.

Becker H 1977. Uma teoria da ação coletiva. Zahar Editores, Rio de Janeiro.

Bourdieu P 1999. A dominação masculina. Ed. Bertrand Brasil, Rio de Janeiro.

Goffman E 1975. Estigma: notas sobre a manipulação da identidade deteriorada. Zahar Editores, Rio de Janeiro.

Goldenberg M 1997. A arte de pesquisar: como fazer pesquisa qualitativa em ciências sociais. Ed. Record, Rio de Janeiro.

Goldenberg M 2000. O macho em crise: um tema em debate dentro e fora da academia, pp. 13-39. In M Goldenberg (org.). Os novos desejos. Ed. Record, Rio de Janeiro.

Goldenberg M \& Ramos MS 2002. A civilização das formas: o corpo como valor, pp. 19-40. In M Goldenberg (org.). Nu e vestido: dez antropólogos revelam a cultura do corpo carioca. Ed. Record, Rio de Janeiro.

Kimmel M 1998. A produção simultânea de masculinidades hegemônicas e subalternas. Horizontes Antropológicos 9(4):103-107.

Mauss M 1974. Sociologia e antropologia. EPU/Edusp. São Paulo.

Pope HG, Phillips KA \& Olivardia R 2000. O complexo de Adonis. Ed. Campus, Rio de Janeiro.

Rodrigues JC 1979. Tabu do corpo. Ed. Achiamé. Rio de Janeiro.

Artigo apresentado em 10/1/2004

Aprovado em 19/5/2004

Versão final apresentada em 12/7/2004 